\title{
Research Article \\ Learning Beyond the Classroom: Teachers' Perspectives of the Extracurricular Activities in Learning English as a Foreign Language
}

\author{
Talal Amara \\ Subratha University, Libya
}

\begin{abstract}
The current study investigated teachers' perspectives of the use of extracurricular activities in the EFL context. Data for the study were collected from 187 questionnaire respondents from Arabic speaking countries. The findings reveal that most EFL teachers in the study context use ECAs in their teaching of English. They also show that teachers not only use these activities to improve language proficiency but also to promote other language-related skills. The findings also reveal some challenges in implementing ECAs such as time convenience, school workload, and lack of funding, some social and cultural barriers, and students' perception of these activities. Based on the findings, the researcher suggests further investigation into some other factors, such as teachers' readiness to implement these activities and the different types of activities that work best for the study context.
\end{abstract}

Key Words: extracurricular, motivation, perspectives, self-confidence

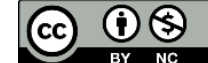

This is an open access article under the CC-BY-NC license.

\section{INTRODUCTION}

Teaching English as a foreign language sometimes fails to achieve its ultimate goals due to certain reasons. Learners spend years learning a foreign language but fail to successfully use it in real-life situations. In most cases, their performance is only limited to the classroom context where certain objectives and curriculum is required. Therefore, language teaching has always been seen as the preparation of learners to use English in a limited situational context. Laili \& Nashir (2018) point out that teachers should select the best way and employ various techniques in the teaching-learning process in order to make their students like what they learn and increase their motivation in learning English as a foreign language. Ideally, the most essential goal of learning English is to prepare learners to communicate successfully in various contexts inside and outside the classroom. That means language learners need to take control of their own learning beyond the gaze of their teachers. Frequent exposure to what is called extracurricular activities (ECAs) can be one option for teachers to improve learners' communication skills. Extracurricular is one option to be able to learn English in a more fun way (Ismailia \& Dewangga, 2017). There is an increasing awareness among teachers and educators of the importance of ECAs in teaching and learning English as a foreign language. These extracurricular activities enhance students' performance and allow them to take the initiative, make independent decisions, and possess communication abilities away from the pressure of evaluation, grades and exams. Extracurricular activities can present what is called autonomous learning, which invites learners to interact in a natural manner.

Corresponding author:

talal.amara@yahoo.com

DOI: https://doi.org/10.31098/jefltr.v1i2.618

Research Synergy Foundation 


\section{LITERATURE REVIEW}

\section{Definition}

There is no unique definition for ECAs that is generally accepted among researchers. Whenever researchers attempt to define them, they describe them in the form of examples of activities (Nelson et al., 2002). ECAs refer to any activities that take place outside of the regular school curriculum context. Nelson et al. (2002) some researchers even use synonyms such as "out-of-class experiences" to describe ECAs (p. 27). These activities reside outside of normal institutional curricula where learners voluntarily choose their way of learning. "The activities are voluntary, and students do not receive grades for academic credit for them" (Holloway, 2000, p. 87). Neither teachers nor their students are required to participate in these extracurricular activities, and none of them receives any remuneration or academic credit for their participation. As stated by Hornby (1995), ECAs categories fall "outside the regular course of work or studies at a school or college" (p. 409). Others acknowledge the relationship between the school setting and ECAs. Stoltzfus (2007) and Vermaas et al. (2009) think that ECAs normally occur outside of school hours, but within the learning setting or via some association with a school, and work with all levels of education - from kindergarten to college. The ECAs were found to be typical of educational settings in a wide range of countries.

\section{Types}

The term extracurricular activities refer to various types of activities that can be done outside the school context, such as debate, athletics, music, drama, school publications, student council, school clubs, contests, and various social events (Emmer, 2010). ECAs can be in the form of a wide range of activities that do not represent the regular school curriculum. Many educational institutions offer a free choice for students to join these activities; however, many private schools believe that such activities help to create more well-rounded students, so they make participation in one or more of these activities mandatory for their students (Stoltzfus, 2007). Examples of the most common ECAs exist in contexts such as academic, athletic, community service clubs, performance organizations, cheerleading clubs, social fraternity, sorority and volunteering (Lariviere, 2016). The definition of the ECAs in the literature, however, makes it difficult to determine what exactly constitutes an extracurricular activity (Bartkus et al., 2012), and so are their types. For the purpose of the current study, the researcher limits the ECAs to language-related tasks such as any activities that are organized by teachers and/or students themselves outside the regular classroom curriculum in order to improve their teaching/learning of English. ECAs are also in the scope of language learning methods and technique development, as they have become more technologically enhanced, e.g., website creation and blogging used for language skills development (Trierweiler, 2009). Computer-Assisted Language Learning formats are also other forms of ECAs (Sylvén \& Sunqvist, 2017). Cope and Kalantzis (2009) describes today's internet-mediated networks and technologies as other forms of formal and informal venues for learners beyond their actual classrooms to access an array of the potential learning environment at any time and place. For example, Web tools, such as emails, chat rooms, social media groups and virtual discussion boards can also help to increase EFL benefits as well as other communication skills.

\section{The Benefits of Extracurricular Activities}

The importance of extracurricular activities is backed by the communicative approach in which EFL learners can develop their communicative, grammatical, and sociolinguistic competencies. These can be in the form of giving speeches, participating in debates, and other social activities. ECAs are very 121 
important and useful for EFL learners who can become productive and create positive attitudes and develop their language skills. With ECAs, students shift from learning mental and logical issues to emotional ones. In other words, students not only learn by verbal instructions in the classroom in a very formal way, but they can also learn by non-verbal instructions during ECAs (Yildiz, 2016). While communicative language learning is perhaps still the most widely spread methodology of language teaching and learning, contemporary research on the effect of ECAs is hardly found. Research studies of ECAs focused mainly on the benefits of their use in school settings and how they affect students' personality, academic performance and social well-being. It is evident that students who participate well in ECAs have greater success in academic institutions as well as life outside the classroom (Ahmad et al, 2019).

The correlation between students' participation in ECAs and their performance in school settings encourages researchers to investigate these assumptions. With ECAs, the learning of foreign languages provides a great chance for students to take responsibility for their own learning into their own hands, which echoes the principles of learner autonomy (Benson, 2001). Participation in ECAs can therefore be seen as a manifestation of an autonomous language learner who attempts to exercise 'pure' autonomy with no direct reflection on their classroom tasks or grades (ibid). Aladjem \& Jou (2016) emphasize "the exposure of learners to the target language beyond school hours" (p. 161), which is particularly important in non-immersive contexts. Eccles (2003) found that students who participate in ECAs achieve better education results and develop a sense of togetherness and responsibility. Hyland (2004) also found that EFL learners, who were engaged in activities outside their classroom such as watching movies, listening to songs and reading academic texts, displayed control of self-determined learning agendas beyond the classroom. Joekel (1985) showed that achievement in extracurricular activities is a factor that can predict success in life beyond college. Gardner et al. (2008) conducted a study about the relationship between students' participation in ECAs in college campus and academic performance. They found out that students who participate in ECAs are more likely to respect diversity, play by the rules, and contribute as a member of a team whether it is sports, scouting or clubs.

Gao (2008) explains that participation in the ECAs demonstrated a willingness to learn, and enhanced learners' levels of self-confidence in a way that can make them more expressive and confident than usual. McGee, et al. (2006) conducted a study on the importance of ECAs and revealed that students who participate in sports show a higher level of relationship towards their colleagues, teachers and parents. In other words, their participation in ECAs enhanced their sense of togetherness and reduce their social anxiety. Penner and Wallin (2012) argued that through music, for instance, students of English can also develop their communication skills with their teachers and classmates in a creative way, using a language that goes beyond verbal skills. Gibbons (2006) conducted a study on the relationship between ECAs and academic achievement for youth and found out that students who were involved in club and sports activities outside their school achieved higher results than their classmates who did not participate. That is, ECAs play an essential role in enhancing academic performance in schools. Kuh, et al., (2008) examined students' involvement in ECAs and the impact on their academic performance and retention during the freshman year. They found out a positive association between students' participation in ECAs, academic achievement and remaining in school for all races and genders. Makarova and Reva (2017) conducted a comparative study of the impact of ECAs on EFL learners in Canadian and Russian contexts.

The study revealed that students perceive ECAs in learning a foreign language as a motivating tool to learn and practice the target language. Students from both contexts reported a positive impact of ECAs 
on building their confidence and developing their communication skills. They also revealed that these activities helped them overcome shyness and anxiety, which are some of the common issues in learning in general and classroom participation in specific. Yildiz (2015) examined the role of ECAs in the success of students' learning of English, and found that there are many advantages of ECAs on students' selfconfidence, motivation and learning of English.

\section{Barriers to extracurricular activities:}

The ability for EFL students to participate in ECAs can be encountered by some factors. Implementing such activities outside school time consumes lots of valuable time in which students or their parents are assigned for other social life and recreational activities (Moreau \& Leathwood, 2006). The ability to take part in these activities is strongly related to students' available time. Moreover, students with too many commitments and tight schedules may have a negative impact on their general school performance if time is well managed and balanced with other school studies (Cheng \& Alc_antara, 2007). Those students who succeed in balancing multiple activities demonstrated higher academic self-efficacy and achievement (Reed \& Kennett, 2017). Kulavic et al. (2013) state that one of three barriers to physical activities is "lack of time" (p. 64). Aguila et al. (2012) found that social class differences reflect equal differences in the type of activities students choose.

In the Arabic speaking context, Malcolm (2004) found that the Bahraini EFL students, for instance, recognize the pedagogic benefits of ECAs, including watching movies and television and speaking to native speakers outside their classroom. Malcolm added that these students display the willingness and confidence to learn beyond the classroom. In another part of Arab countries, Palfreyman's (2006) conducted a research study on tertiary level female Emirati EFL learners and realized that these learners also favored utilizing entertainment and communication as ECAs. Normah (2017) also investigated teachers' attitudes towards the use of ECAs in enhancing students' speaking skills in Saudi Arabia. He found that teachers share positive attitudes towards the use of ECAs in English classes, but the way they use them is not appropriate.

In brief, the literature shows that there is a shortage of studies on how teachers perceive ECAs, particularly in Arabic speaking countries. The present study, therefore, is an attempt to bridge this gap in the literature by examining EFL teachers' perspectives of ECAs in Arab countries. It is especially important for educators to know and design pedagogical support for learning through ECAs.

\section{RESEARCH METHOD}

The current study was conducted within the interactionist theory framework of language acquisition which considers communication interaction as an essential tool to language development. Lariviere (2016) asserts that English language learners need not only academic exposure but also a suitable environment to develop their interpersonal language skills through social contexts. ECAs offer students the opportunity to improve these interpersonal skills in English by acting and interacting in various situations within their social contexts. The current study was also grounded in the 'natural approach' in which students acquire the target language in a natural way by participating in real-life learning activities such as interviews, video conferences and speech contests (Normah, 2017). This learning approach is different from ordinary curricular-based learning.

The study was also constructed within the framework of mixed methods, which complements the constructivist paradigm that allows multiple types of data as described by Patton (2005). This mixedmethod (i.e. quantitative and qualitative) design enabled the researcher to collect numerical and 123 
descriptive data that was used to investigate teachers' perspectives of ECAs in learning English as a foreign language. The researcher determined a core set of questions to approach teachers' perspectives of ECAs from various angles. The study is centered on the following questions: Do teachers use ECAs in their teaching of English as a foreign language? What kind of ECAs are commonly used in teaching EFL in Arabic speaking countries? Do they believe these ECAs are effective in learning English as a foreign language? What are the most potential benefits and challenges of implementing ECAs in Arabic speaking countries? This study examined teachers' perspectives of the use of extracurricular activities and their impact on EFL learners. It relied on questionnaires to collect the data from a random number of EFL across the Arab countries. The use of questionnaires has been routinely used by researchers in sociolinguistic and education studies and yielded outstanding results (Normah, 2017; Zakhir \& O'Brien, 2016). The questionnaire included both close-ended as well as open-ended questions which enabled the researcher to collect numerical and descriptive results. The use of this instrument offered a mixed quantitative and qualitative analysis of the collected data. The researcher argued that using open-ended questions in computerized survey is simple, inexpensive and less time-consuming. Furthermore, the open-ended questions helped the researcher to gain deeper insight into EFL teachers' perspectives and preferences towards the use of extracurricular activities for improving the different language skills and to highlight their opinions, suggestions, anticipated obstacles and expectations.

At this stage, it was important to search for descriptive responses that cannot easily be collected in large international samples. The researcher used the Google Form to design the questionnaire and distributed it using many social media pages and groups. The researcher used this questionnaire design to give respondents a chance to further explain their answers, explore their own perspectives, and investigate preferences for different ECAs. The researcher received responses from 187 (61\% female 38\% male) EFL teachers teaching in different Arab countries, including Mauritania, Morocco, Algeria, Tunisia, Libya, Egypt, Saudi Arabia and Sudan. All participants teach different language skills at different levels of proficiency. The research has no prior knowledge of whether or not these randomly selected participants use ECAs. All the numerical responses were collected, highlighted, and grouped in themes based on their consistency and occurrence. Other responses that were not consistent with the main themes were extracted for the focused investigation of the topic.

\section{FINDINGS}

To find out whether or not participants use ECAs with their EFL students, the researcher asked the participants if they use any type of these activities. The questionnaire responses reveal that the majority of the respondents, 95\% use different types of ECAs with their students to support their learning of different language skills. In a follow-up question about the frequency of using ECAs, of that number, 58\% of them always use ECAs, whereas $30 \%$ sometimes use them. Only $11 \%$ of the participants say that they rarely use activities for some reason (Fig. 1). 


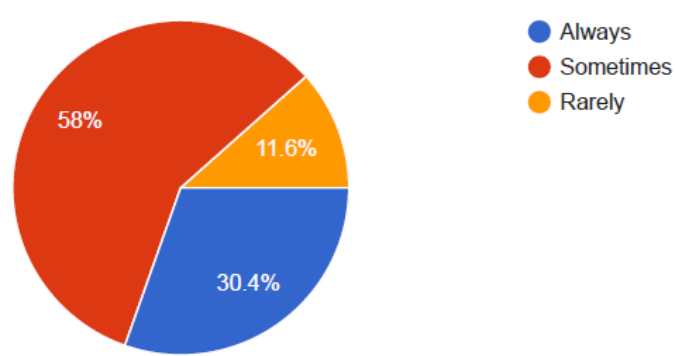

Figure. 1

Questionnaire responses also reveal that the teachers vary in the way they use ECAs as some of them $56 \%$ use ECAs online, whereas $40 \%$ use them in person (Fig. 2 ).

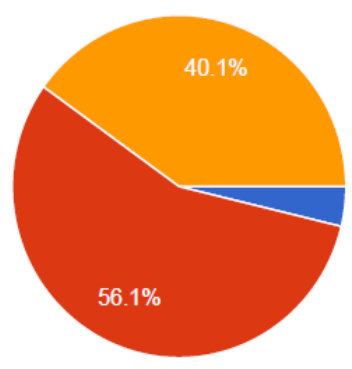

Online

In person (Face-to-Face)

Both

Figure. 2

In response to the second research question, participants were asked about the types of ECAs used in the research context. The responses reveal that the most commonly used activities used with participants include games, competitions, internet surfing, debates, conferences \& workshops, and social clubs (Fig. 3).

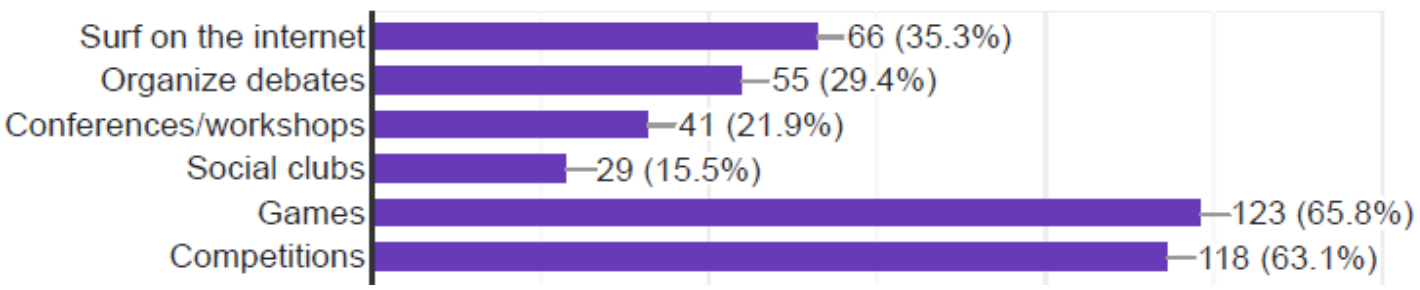

Figure. 3

With regard to the purpose of using ECAs, respondents had similar reasons for using these activities. More than $72 \%$ of participants agree that they use ECAs to improve language proficiency and to increase students' motivation to learning, whereas $69 \%$ say that the purpose of using these activities is to improve students' confidence. Others add that other purposes can be the reasons beyond the use of ECAs, including the development of communication skills (58\%), the increase of students' social skills (42\%), and breaking cross-cultural barriers (32\%) as shown in (Fig. 4).

125 


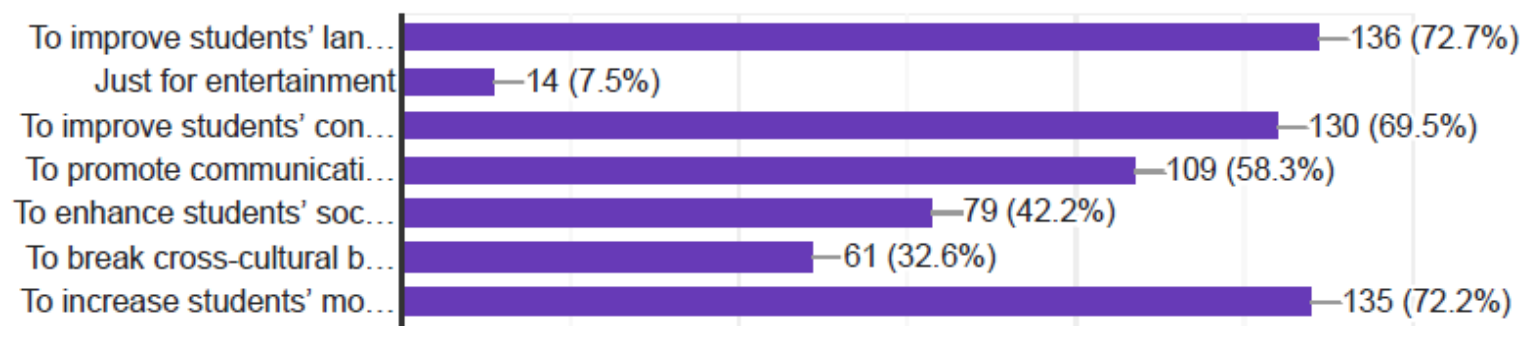

Figure. 4

In response to the third research question about the effectiveness of ECAs, all participants agree that ECAs have a positive impact on EFL students in one way or another. Moreover, they agree that these activities are not limited to certain language proficiency levels but are effective with all different language levels. However, the participants agree in terms of the target students as the majority (70\%) agree that ECAs are more effective with young learners, while 59\% of them think that ECAs can be effective even with teenage learners. This finding aligns with the findings of the Ontario Public School Boards' Association that ECAs encourage lifelong understanding and prepare young students for life beyond academic success (Sarson, 2005). These views echoed Massoni (2011) who states that "When students participate in extracurricular activities, especially at a young age, it teaches them about long term commitments" (p. 86). Daley and Leahy (2003) also argued that participating in ECAs may enhance young learners' mental wellbeing by reducing stress.

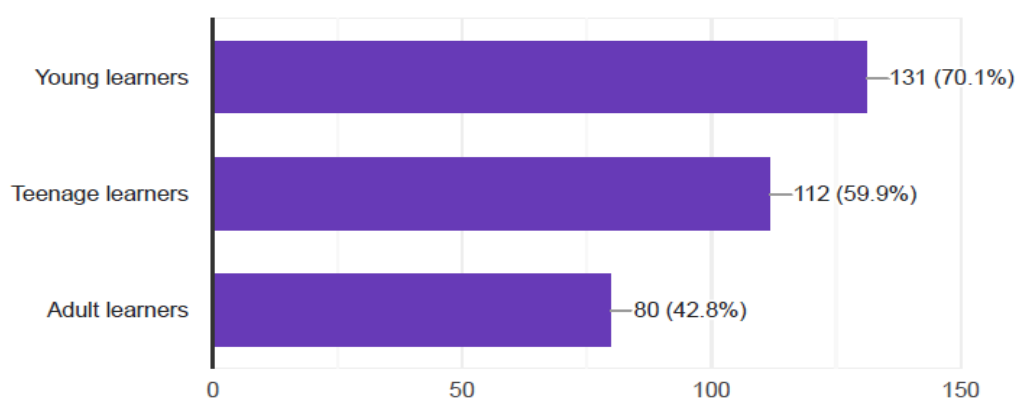

Figure. 5

The current study reveals that there is a consensus among participants regarding the effectiveness of ECAs on certain aspects of EFL context. The findings show that almost $75 \%$ of the participants believe that ECAs are effective in improving language proficiency as well as communication skills. King et al. (2020) show that a male immigrant student, Sam, explained that his volunteer work at a retirement home allowed him to improved his communication and English language skills. Park \& Choi (2009) state that in order to improve student's language proficiency, it is important to provide learners with the opportunity for interaction within the ECAs that effectively support them in the social learning context. Makarova and Reva (2017) showed a positive effect of ECAs on the overall language proficiency as well as on all language skills. Other participants (81\%) believe that these activities can also be effective in improving students' selfconfidence. This finding reassures that ECAs increase students' self-confidence by making them members of a group and creating a suitable atmosphere for accountability among the group. Reeves (2008) argued that ECAs are necessary for improving students' self-confidence and personality. Yildiz (2015) found that 
there are many advantages of ECAs on students' self-confidence and the learning of English. Others (60\%) point out that these activities not only are limited to the acquisition of the linguistic part of the language but also to enhancing students' social skills among colleagues. Students who participate in ECAs meet many new people in each workshop, club, sport, game, and in all different groups. Many times, the people are students that they would never talk to and become friends with. In different activities, students learn about group work, play important roles, and sometimes end up having less conformity to cross-gender stereotypes. That is, ECAs become a part of students' everyday life. As teachers, we need to be fully aware of the effects that these activities have on education in general and on learning a foreign language in specific. González, Moll, \& Amanti, 2013) state that learning knowledge in social life is not found in textbooks, rather through exposure to life experiences and achieved among members of social communities. Students in ECAs experience a better chance to build up their own character and social skills. Willms (2003) argues that students are aware of the necessity of teamwork, responsibility, commitment, and hard work. Through ECAs, students learn how to manage their time and not to waste it on unimportant things. ECAs can also play a crucial role in developing students' social skills along with language skills which, in turn, can help them to change their life and get better chances to succeed in life (Hudson, 2000).

Furthermore, others (82\%) believe that these activities are effective in increasing students' motivation towards learning experiences. Some of the participants point out that ECAs can provide an opportunity for students to use English in an authentic situation rather than a limited classroom setting. With ECAs, students, for example, have the chance to unconsciously use their English in a workshop discussion or debates. Dornyei (2001) enlightens that keeping motivation high in language teaching and learning is a key factor in successful language acquisition as students' academic achievement is strongly related to their motivation. ECAs can be a good motivational power in a school setting where students are willing to spend most of their time in such activities. Reeves (2008) argues that students who participate in ECAs are more likely to remain in school and attend classes in comparison to those who do not take part in these activities. This can be justified by the rich environment that ECAs offer for students to exploit their own abilities and skills. That is, students' motivation level is considered an important factor that affects their quality of foreign language learning (Sengkey \& Galag, 2018). Çelik \& Bayraktar Çepni (2020) stress the importance of inner motivation in foreign language teaching.

Respondents were also asked about the existence of any obstacles in implementing ECAs in EFL context. There is a consistency among the responses that there are five main obstacles encountering the implementation of ECAs in the study context (Fig. 6).

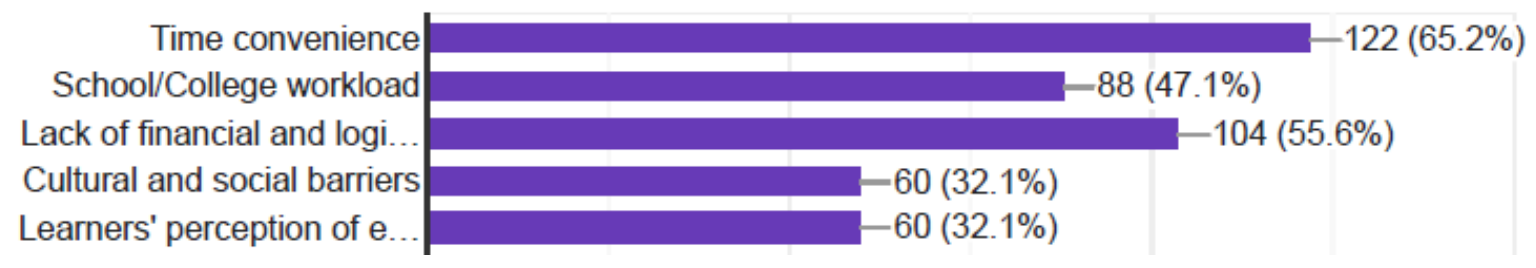

Figure 6

$65 \%$ of the participants indicate that time convenience for students is one of the main issues in designing any extracurricular activities for students. Yildiz (2016) argues that students at school may think that ECAs may be time-consuming; however, these activities might be a great support for their future careers. Zafariddinovna (2021) also suggests that ECAs keep students refreshed both physically and mentally and help them to wisely manage their time. Kulavic et al. (2013) state that one of the top barriers 127 
to physical activities was "lack of time" (p. 64). Current study responses may refer to the fact that there are no sufficient and suitable time for out-of-class activities since students' schedule is already full of homework and other school assignments. However, students are strongly advised to take part in these activities even on a minimum range that does not affect their school work and duties. Students can also use public and summer holidays to participate in any type of ECAs.

Other participants (55\%) also complain about the lack of financial and logistic aids that can help in designing extracurricular activities outside the school setting. $47 \%$ of the participants point out that school or college workload such as homework and assignments are considered an issue in students' participation in any extracurricular activities. King et al. (2020) found out that the timing of the activities, as well as the cost of these activities, may be barriers to participation for students who balance multiple demands. Kulavic et al. (2013) also found out that nontraditional students reported a lack of resources as barriers to their participation in ECAs.

Only $32 \%$ of the respondents complain about students' cultural and social barriers that may decrease student participation in the ECAs. In fact, language students are not expected to know only the language, but also its culture. ECAs in EFL context are sometimes made up of students with heterogeneous backgrounds and abilities which enable them to work together to succeed in groups. In other words, ECAs can be a chance for students to appreciate differences in skills, aptitudes, learning styles, personalities and interests. Nimchahi, Jamshidov \& Khorshidi (2019) clarify that the main objective of ECAs is to interest students in gaining knowledge about the target language knowledge, culture, and people so that they become aware of the diversity of the globe. This way students achieve a positive attitude towards learning about other cultures. Aoujil \& Benattabou (2021) found out that ECAs can also bring positive effects on the social relationships among all students. That is, educators sometimes consider that difference between educational cultures and ways of learning that students and parents are accustomed to as a challenge. Derderian-Aghajanian \& Wang (2012) argue that students not only have to adjust their language patterns and thinking in order to understand English language but they also have to learn the target language learning culture and habits.

Another $32 \%$ of the study responses show that students' perception of ECAs may also affect their participation in these activities. It is really crucial that students perceive the ECAs as a method of learning English; otherwise, it may become a waste of time and result in low achievement in school. In most developing countries, traditional methods are generally being used in learning English as a foreign language where students do not have enough space and time to practice their speaking. Students' attitude towards learning English becomes negative as a result of their perceptions and assumptions about learning a foreign language. Albayrak \& Şener (2021) suggests that curriculum designers should raise the policymakers' awareness and create an initiative for a change of practice in the field of foreign language learning. That can be done through in-service training programs that explain what ECAs are and how they should be implemented to go in line with the formal curriculum. That can also be through changing students' perception towards English learning (Tatar, 2017). That is, teachers should encourage students to be active participants in these activities. Participation in these activities will definitely increase students' perception of competence and consequently has a positive impact on their performance at a higher academic level (Holland \& Andre, 1987).

On the other hand, some researchers have a different point of view of the outcome of the ECAs in learning. Brown (1988) criticized the claims made by Holland and Andre (1987), who argued that participation in ECAs in high school correlated with higher levels of self-esteem, improved race relations, 
and involvement in social activities in young adulthood. Brown described these findings as "an unduly beneficent or optimistic summary of many studies and stops short of the decisive directives needed to yield more enlightening studies" (p. 107). He added that if there are four major objectives to be achieved during the ECAs, these activities can be categorized according to their primary objective and may neglect the outcome of the other objectives. He emphasized that researchers not only should focus on the outcome of these activities but also on their process. This can also help researchers examine the outcome of each objective and eliminate any type of generalizability.

\section{CONCLUSION}

The findings of this study proved that all participating teachers perceived ECAs as very beneficial in learning English as a foreign language. Participants' most common activities are competitions, games, debates, conferences and workshops. They all agree that these activities improve language proficiency and positively impact other aspects of learning such as self-confidence, communication skills, motivation towards learning, social skills, and raise target language culture awareness. However, most of them identify some obstacles in implementing some activities and achieving the best of them. Time convenience is also viewed as the main obstacle as ECAs are not formally part of the curriculum, which assigns a very short time for English in most educational institutions. Similarly, participants complain about students being overloaded with school homework and assignments, which may also affect their participation in these activities. Some participants also link their participation in these activities with their cultural and social values that may reduce the chances of participation. Most ECAs require sort of financial and logistic support either from educational institutions or families. This raises a question for a further investigation into the type of participants who are willing to take part in these activities as low-income families may choose to participate in certain activities but not others. One important challenge that was brought up by the study participants is how students perceive the out-of-class activities. If these activities are not well-designed and prepared, students may use them only for entertainment and end up with minimum benefits.

To conclude, extracurricular activities should be embedded in the formal curriculum in teaching English as a foreign language. However, to implement these activities, students, teachers and curriculum designers should prepare a detailed plan of what, whom, when, and how long to use these activities so that a positive outcome is highly expected. This will definitely support the idea of Galbraith (1990) about a positive learning environment that involves learners in mutual planning of curriculum and helps learners to carry out their learning plans. One gap in the literature that may attract other researchers is whether or not teachers are well trained to carry out ECAs in the EFL context. Examining such factors may reveal new findings in the outcome of ECAs in EFL learning. Teachers, therefore, should be well trained on how to integrate speaking with other skills. Moreover, all members involved in the ECAs, including teachers, supervisors, school administrators, and curriculum designers, should work together to achieve the best of these activities.

\section{REFERENCES}

Aguila, C., Sicilia-Camacho, A., \& Roberts, K. (2012). Youth culture, postmodernism, and social divisions: an exploration of activities, restrictions, and expenditures in the leisure of Spanish university students. Journal of Leisure Research, 44(1), 88-109.

Ahmad, M., Rahman, M. F., Ali, M., Rahman, F. N., \& Al Azad, M. A. S. (2019). Effect of Extracurricular Activity on Student's Academic Performance. Journal of Armed Forces Medical College, Bangladesh, 11(2), 41-46.

129

ISSN 2776-4524 (Online) | 2776-4184 (Print) 
Aladjem, R., \& Jou, B. (2016). Informal language learning in authentic setting, using mobile devices and SNS. International Conference on e-Learning (pp. 161-164). Lisbon: IADIS.

Albayrak, H., \& Şener, T. (2021). The relationship between participation in extracurricular activities and motivation of foreign language learning. International Journal of Psychology and Educational Studies, 8(2), 122-132.

Aoujil, S., \& Benattabou, D. (2021). The Impact of Extracurricular Activities on Language Learning:'Access Program in Morocco as a case study. International Journal of Linguistics, Literature and Translation, 4(2), 185-195.

Bartkus, K. R., Nemelka, B., Nemelka, M., \& Gardner, P. (2012). Clarifying the meaning of extracurricular activity: A literature review of definitions. American Journal of Business Education (AJBE), 5(6), 693-704.

Benson, P. (2001). Teaching and researching autonomy in language learning. Harlow: Pearson Education

Brown, B. B. (1988). The vital agenda for research on extracurricular influences: A reply to Holland and Andre. Review of Educational Research, 58(1), 107-111.

Çelik, S., \& Bayraktar Çepni, S. (2020). Turkish university students' experiences of learning English: Is English class a dark forest or a clear sky? Novitas-Royal (Research on Youth and Language), 14(2), 97-118.

Cheng, D. X., \& Alcantara, L. (2007). Assessing working students' college experiences: A grounded theory approach. Assessment \& Evaluation in Higher Education, 32(3), 301-311.

Cope, B., \& Kalantzis, M. (2009). New media, new learning. In Multiliteracies in motion (pp. 99-116). Routledge.

Daley, A. J., \& Leahy, J. (2003). Self-perceptions and participation in extracurricular physical activities. Physical Educator, 60(2), 13.

Derderian-Aghajanian, A., \& Wang, C. C. (2012). How culture affects on English language learners(ELL's) outcomes, with Chinese and Middle Eastern Immigrant Students. International Journal of Business and Social Science, 3(5).

Eccles, J. S., Barber, B. L., Stone, M., \& Hunt, J. (2003). Extracurricular activities and adolescent development. Journal of Social Issues, 59(4), 865-889.

Emmer, R. (2010). Community service. New York, NY: Rosen Publishing Group.

Galbraith, M.W. (ed.) (1990). Adult learning methods. Florida: Krieger. Publishing Company.

Gao, X. (2008). The 'English Corner' as an out-of-class learning activity. ELT Journal, 63(1), 60-67.

Gardner, M., Roth, J., \& Brooks-Gunn, L. (2008). Adolescents' participation in organized activities and developmental success 2 and 8 years after high school: Do sponsorship, duration, and intensity matter? Developmental Psychology, 44(3), 814-830.

Gibbons, J. (2006). The link between extracurricular activities and academic Achievement for Youth in Grades 5 and 7.

González, N., Moll, L. C., \& Amanti, C. (Eds.). (2013). Funds of knowledge: Theorizing practices in households, communities, and classrooms. New York: Routledge

Holland, A., \& Andre, T. (1987). Participation in extracurricular activities in secondary School: What is known, what needs to be known? Review of Educational Research, 57, 437-466.

Holloway, J. H. (2000). Extracurricular activities: The path to academic success. Educational Leadership, 57(4), 87-88. 
Hornby, A.S. (1995). Oxford Advanced Learner's Dictionary. New International Students' Edition. Oxford: Oxford University Press.

Hudson, G. (2000) Essential Introductory Linguistics: Blackwell Publishers.

Hyland, K. (2004). Genre and second language writing. University of Michigan Press.

Ismailia, T., \& Dewangga, V. (2017). Pelatihan News Reading dan Story Telling untuk English Club di SMAN Kalisat. J-Dinamika: Jurnal Pengabdian Masyarakat, 2(1).

Joekel, R. G. (1985). Student activities and academic eligibility requirements. Nassp Bulletin, 69(483), 3-9.

King, A. E., McQuarrie, F. A., \& Brigham, S. M. (2020). Exploring the relationship between student success and participation in extracurricular activities. SCHOOL: A Journal of Leisure Studies and Recreation Education, 1-17.

Kuh, G. D. (2008). High-impact educational practices: What they are, who has access to them, and why they matter. Association of American Colleges \& Universities.

Kulavic, K., Hultquist, C. N., \& McLester, J. R. (2013). A comparison of motivational factors and barriers to physical activity among traditional versus nontraditional college students. Journal of American College Health, 61(2),60-66.

Laili, R. N., \& Nashir, M. (2018). The Effect of Blended Learning by Using Edmodo in Teaching English for Nursing Students. Indonesian Journal of Curriculum and Educational Technology Studies, 6(2), 7176.

Lariviere, M. L. (2016). Extracurricular activity participation and English language learners: second language acquisition and academic performance. Sam Houston State University.

Makarova, V., \& Reva, A. (2017). Perceived impact of extracurricular activities on foreign language learning in Canadian and Russian university contexts. Apples: Journal of Applied Language Studies, 11.

Malcolm, D. (2004). Why should learners contribute to the self-access centre?. ELT Journal, 58(4), 346-354.

Massoni, E. (2011). Positive effects of Extracurricular activities on students. Essai, 9(1), 27.

McGee, R., Williams, S., Howden-Chapman, P., Martin, J., \& Kawachi, I. (2006). Participation in clubs and groups from childhood to adolescence and its effects on attachment and self-esteem. Journal of adolescence, 29(1), 1-17.

Moreau, M.-P., \& Leathwood, C. (2006). Balancing paid work and studies: Working (-class) students in higher education. Studies in Higher Education, 31(1), 23-42.

Nelson, I. T., Vendrzyk, V. P., Quirin, J. J., \& Allen, R. D. (2002). No, the sky is not falling: Evidence of accounting student characteristics at FSA schools, 1995-2000. Issues in Accounting Education, 17(3), 269-287.

Nimchahi, A., Jamshedov, P., \& Salimi Khorshidi, A. (2019). The Effect of Extracurricular Activities on SocioCultural Competence of EFL Students. Critical Literary Studies, 1(2), 99-121.

Normah, Y. (2017). Teachers' Attitudes towards the use of Extracurricular Activities in Enhancing Students' Speaking Skills. International Journal of Academic Research in Progressive Education and Development, 6(3).

Palfreyman, D. (2006). Social context and resources for language learning. System, 34(3), 352-370.

Park, Ji-H., \& Choi, H. J. (2009). Factors Influencing Adult Learners' Decision to Drop Out or Persist in Online Learning. Journal of Educational Technology \& Society, 12(4), 207-217.

Patton, M. Q. (2005). Qualitative Research. New Jersey: John Wiley and Sons.

Penner, C., \& Wallin, D. (2012). School attachment theory and restitution processes: Promoting positive behaviors in middle years schools. Canadian Journal of Educational Administration and Policy, (137), 36.

131

ISSN 2776-4524 (Online) | 2776-4184 (Print) 
Reed, M. J., \& Kennett, D. J. (2017). The importance of university students' perceived ability to balance multiple roles: A comparison of students with and without disabilities. The Canadian Journal of Higher Education, 47(2), 71-86

Reeves, D. B. (2008). The extracurricular advantage. The Positive Classroom. Educational Leadership, 66(1), 86-87.

Sarson, L. A. (2005). Ontario high school sport: an Investigation of Organizational Design and its Context. Canada: Brock University

Sengkey, V. G., \& Galag, E. H. (2018). Student attitudes and motivation in learning English. Catalyst, 17, 115122.

Stoltzfus, C. D. A. (2007). Study of the correlation between participation in extracurricular activities and academic performance of middle level and high school students. MA Thesis. The Pennsylvania State University.

Sylvén, L. K., \& Sunqvist, P. (2017). Computer-assisted language learning (CALL) in extracurricular/extramural contexts. CALICO Journal, 34(1).

Tatar, S. (2017). An overview of research on second/foreign language learner motivation and future directions. Çukurova University Faculty of Education Journal, 46(2), 697-710.

Trierweiler, H. (2009). Summer scribbles. Instructor, 118(6), 58-58.

Vermaas, S. J. G. (2009). Extracurricular Activities at School: The relationship between specialization in subject areas and exit level and the extracurricular activities of high school students (Master's thesis).

Willms, J. D. (2003). Student engagement at school: A sense of belonging and participation: Results from PISA 2000. Publications de l'OCDE.

Yildiz, Y. (2015). The key to success in English learning can be involvement in extracurricular. International Journal of Thesis Projects and Dissertations (IJTPD), 3(3), 24-28.

Yildiz, Y. (2016). Impact of language-oriented extracurricular activities on academic achievement in Language preparation schools. Journal of Education in Black Sea Region, 1 (2), 161-171.

Zafariddinovna, A. Z. (2021). Organization of Extracurricular Activities in a Foreign Language. Academician Globe: Inderscience Research, 2(05), 582-589.

Zakhir, M., \& O’Brien, L. J. (2016). French neo-colonial influence on Moroccan language education policy: a study of current status of Standard Arabic in science disciplines. Language Policy, 39-58. 